\title{
Degradation of Discarded used Engine Oil by Pseudomonas aeruginosa DP-1 and its Optimization
}

\author{
Dipti R. Parikh ${ }^{1}$, Devayani R. Tipre ${ }^{1}$, Nisha S. Nayak ${ }^{1}$ and Shailesh R. Dave ${ }^{2 *}$ \\ ${ }^{1}$ Department of Microbiology and Biotechnology, School of Sciences, Gujarat University, \\ Ahmedabad 380009, Gujarat, India \\ ${ }^{2}$ Xavier's Research Foundation, Loyola Centre for Research and Development, St. Xavier \\ College campus, Navrangpura, Ahmedabad-380009, Gujarat, India \\ *Corresponding author
}

\begin{abstract}
A B S T R A C T
Keywords

Pseudomonas

aeruginosa; Used engine

oil, Biodegradation,

Optimization

Article Info

Accepted:

20 March 2018

Available Online:

10 April 2018

Oil degrading organisms were enriched in MSM medium supplemented with used engine oil. Organisms showed zone of clearance of 7-24 mm on TBA and 3-16 mm on used engine oil supplemented MSM plate. The \% degradation of used engine oil was 14 to $37 \%$. Isolate DP-1 showed highest activity, it was identified as Pseudomonas aeruginosa DP-1 by $16 \mathrm{~S}$ r-RNA gene sequencing analysis. The organism gave 2, 6-dichlorophenol indophenol test positive. After optimization the used engine degradation was as high as $68 \%$ in 32 days of incubation. Selection and optimization resulted in 1.8 fold increase in used engine oil degradation potential of the organism.
\end{abstract}

\section{Introduction}

Petroleum hydrocarbons and its derivatives, such as engine oil, diesel oil, mineral oil, and heavy oil residues have a serious threat on the environment. They have been classified as most hazardous pollutants ( $\mathrm{Su}$ et al., 2011, Udeani et al., 2009). Engine oil is a mixture of base polycyclic aromatic hydrocarbons (PAHs) having saturated and unsaturated long-chain with C16-C36 carbon length, cyclic alkanes and additives such as anticorrosive, antiwearing and antitearing agents (Koma et al., 2003). On the other hand, used oil contain additive, some metals such as lead, zinc, barium and magnesium resulting from engine wear and tear and higher percentages of alkyl benzenes, naphthalene, methyl naphthalene and higher PAHs due to pyrosynthesis (Dominguez-Rusado et al.,2003; Lu S-T et al., 2008). Used engine oil contains more amounts of carcinogenic PAHs as well as heavy and toxic metals compare to the fresh engine oil. Thus, it founds a potential threat to humans, animals, and vegetation (Adelowo et al., 2006). Used engine oil contaminated soil and water resources have been treated by chemical and physical 
methods however, these methods are transfer pollution from one phase to another like soil to water or air and also they are cost intensive (Huang et al., 2009).

Bioremediation is found to be the best alternative especially microbial degradation, in which microorganisms are used to degrade pollutants (Akio et al., 2006). Transformation, polymerization and mineralization are the potential mode to detoxify hazardous pollutant by microbes. Many times single strain are capable of degrading a limited components of the pollution component, whereas complete biodegradation require mutual activities of several strains called consortium (Wang et al., 2007; Lal and Khanna, 1996). However, there is increasing research on the isolation of individual organisms that can not only degrade the major components of engine oils but also demonstrate versatility for other recalcitrant hydrocarbons, as these pollutants are mostly found together in the same environmental compartments.

The study was carried out for the assessment of biodegradation of used engine oil by Pseudomonas aeruginosa DP-1 and optimization of some parameters, as the organism is previously reported as a hydrocarbon degrader, but not used for discarded used engine oils.

\section{Materials and Methods}

\section{Collection of soil sample}

Used engine oil contaminated soil samples were collected in polythene bag from 3 locations of Ahmedabad Municipal Transport Service (AMTS) workshop Jamalpur, Ahmedabad. The collected samples were mixed to prepare composite soil sample. The composite sample was brought to lab and preserved in refrigerator.

\section{Collection of used engine oil}

Discarded used engine oils $2 \mathrm{~T}$ and $4 \mathrm{~T}$ were collected from garage in sterile plastic bottle and they were mixed.

\section{Isolation of used engine degrading bacteria}

The used engine oil contaminated soil sample $10 \mathrm{~g}$ was added in $100 \mathrm{~mL}$ MSM medium. MSM medium was supplemented with $1 \%$ $(\mathrm{v} / \mathrm{v})$ sterile $(0.2 \mathrm{~mm}$ Millipore membrane filter) used engine oil as carbon source. Inoculated flask was incubated at $35 \pm 2{ }^{\circ} \mathrm{C}$ and $100 \mathrm{rpm}$.

After 1 week of incubation $1 \mathrm{~mL}$ of enriched sample was serially diluted to $10^{-4}, 10^{-5}$ and $10^{-6}$, from the diluted sample $0.1 \mathrm{~mL}$ sample was spreaded on sterile MSM and nutrient agar plates and both the plates were over layered with $0.1 \mathrm{~mL}$ of sterile used engine oil and plates were incubated at $35 \pm 2{ }^{\circ} \mathrm{C}$ for three days.

Well isolated colonies with distinct colony morphology on MSM agar were selected and purified on MSM agar by streak plate method. Procedure was repeated for three times and well isolated colonies were selected and preserved on nutrient agar slants

\section{Screening of isolates}

From all the 15 selected isolates $1 \mathrm{~mL}(\mathrm{v} / \mathrm{v})$ inoculum $\left(3 \times 10^{7}\right.$ cells $\left.\mathrm{mL}^{-1}\right)$ was inoculated in $50 \mathrm{~mL}$ MSM medium supplemented with 0.5 $\mathrm{mL}$ sterile used engine oil all the flask were incubated at $35 \pm 2^{\circ} \mathrm{C} 100 \mathrm{rpm}$. Degradation of used engine oil was estimated with gravimetric method (Black CA 1965).

To confirm the degradation of tributyrine, 50 $\mu \mathrm{L}\left(3 \times 10^{7}\right.$ cells $)$ of all the isolated cultures were spot inoculated on tributyrine agar (TBA) plates in triplicates and plates were 
incubated at $35 \pm 2{ }^{\circ} \mathrm{C}$. Zone of clearance were measured and average of 3 observations were recorded. The culture which showed highest degradation of used engine oil and largest zone of clearance on TBA was selected for further study.

Detection of hydrocarbon utilization by 2 , 6-DCPIP

To detect oxidative utilization of hydrocarbon from used engine oil $1 \mathrm{~mL}\left(3 \times 10^{7}\right.$ cells $)$ of isolate DP-1 was mixed with $15 \mu \mathrm{L}$ of sterile used engine oil and sterile $40 \mu \mathrm{L}$ of $0.01 \% 2$, 6-dichlorophenol indophenol. Inoculated tubes were incubated for $48 \mathrm{~h} 35 \pm 2^{\circ} \mathrm{C}$. Oxidation of hydrocarbon was determine based on decolorization of added 2, 6-DCPIP (Hanson et al., 1993).

\section{Optimization of used engine oil biodegradation}

If otherwise mention the experiment condition were $\mathrm{pH} 7$ incubation temperatures $35 \pm 2^{\circ} \mathrm{C}$ used engine oil concentration $1 \% \mathrm{v} / \mathrm{v}$ and inoculum $1 \mathrm{~mL}(\mathrm{v} / \mathrm{v})$ having $3 \times 10^{7}$ cells. All inoculated and control flasks were incubated for 32 days and amount of used engine oil degradation was measured by gravimetric method.

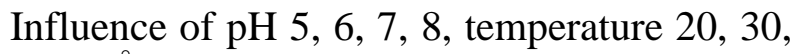
$35,50^{\circ} \mathrm{C}$, concentration of engine oil $1,2,3$, $4 \%$, and amount of inoculum size 1, 2, 3, 4\%, were studied in MSM by modifying these parameters as required under the mentioned conditions.

\section{Results and Discussion}

\section{Isolation and screening}

Enriched sample of used engine oil in MSM broth showed 42 morphological different colonies on nutrient agar plates and 15 different types of colonies on MSM agar plates (Fig. 1). Used engine oil degradation zones of 15 colonies on used engine oil supplemented MSM agar plates were in the range of 3 to $16 \mathrm{~mm}$ and on TBA plates the zones were 7 to $24 \mathrm{~mm}$. Isolates showed 14 to $37 \%$ of used engine oil degradation in 32 days of incubation. Isolate DP-1, DS-7, DP-4 showed $30 \%$ and above degradation whereas isolate DS-6, DS-5 and OP gave less than $20 \%$ of degradation (Table 1).

\section{Confirmation of oxidative utilization test}

Isolate DP-1 which showed highest zone of used engine oil degradation, highest zone on TBA plate and highest percentage of used engine oil degradation. The isolate also showed decolorization of 2, 6-DCPIP in $48 \mathrm{~h}$ of incubation (fig. 2), indicated hydrocarbon oxidative test positive, thus this isolate was selected for further study.

\section{Identification}

Potential isolate DP-1 was identified as Pseudomonas aeruginosa based on $16 \mathrm{~S}$ rRNA gene sequence analysis. The sequence was deposited in NCBI with accession number MG976750.

\section{Optimization}

Influence of $\mathrm{pH}$ on oil degradation was studied and results are shown in figure 3 (a). Highest degradation was observed at $\mathrm{pH} 7$. The acidic $\mathrm{pH}$ was less influencing compare to alkaline $\mathrm{pH}$. Increases in $\mathrm{pH}$ on alkaline side ( $\mathrm{pH} 7$ to 8) was found to exert more inhibition of used engine oil degradation compare to same decrease on acidic side (pH 7 to 6).

Influence of inoculum size is shown in figure 3 (b). Inoculum size of $3 \times 10^{7}$ cells, $6 \times 10^{7}$ cells, $9 \times 10^{7}$ and $1.2 \times 10^{8}$ cells in the system show marginal variation, and degradation was in the range of 59 to $60 \pm 2 \%$. 
These could be due to growth of used engine week of incubation, and the results reported oil degrading organisms which could have resulted in almost equal cell numbers after 1 were of 32 days of incubation.

Table.1 Screening of isolates for degradation of used engine oil (UEO) and tributyrin (TB)

\begin{tabular}{|l|c|c|c|}
\hline Isolate & \multicolumn{2}{|c|}{ Zone of clearance (mm) } & Degradation of UEO \\
\hline & TB & UEO & \% \\
\hline Control & 0 & 0 & 0 \\
\hline DP1 & 24 & 16 & 37 \\
\hline DS1 & 22 & 12 & 31 \\
\hline DS2 & 19 & 12 & 30 \\
\hline DS3 & 16 & 11 & 20 \\
\hline DS4 & 15 & 12 & 26 \\
\hline DS5 & 12 & 5 & 17 \\
\hline DS6 & 9 & 3 & 14 \\
\hline DS7 & 21 & 8 & 36 \\
\hline MSMa & 19 & 12 & 28 \\
\hline MSMb & 14 & 9 & 24 \\
\hline YP & 19 & 13 & 25 \\
\hline OP & 7 & 3 & 18 \\
\hline Z1 & 20 & 14 & 26 \\
\hline $\mathbf{Z 2}$ & 15 & 11 & 29 \\
\hline Z3 & 20 & 15 & 27 \\
\hline
\end{tabular}

Fig.1 Zone of degradation on MSM overlayered with UEO

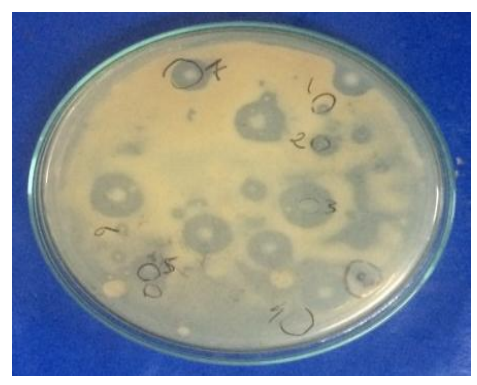

Fig.2 Hydrocarbon utilization by 21, 6-DCPIP oxidation test a) No oxidation b) oxidation positive

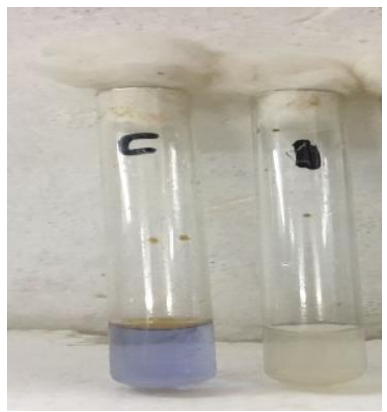
a)
b) 
Fig.3 Effect of different parameters; (a) pH, (b) innoculum size, (c) temparature and (d) UEO concentration

(a)

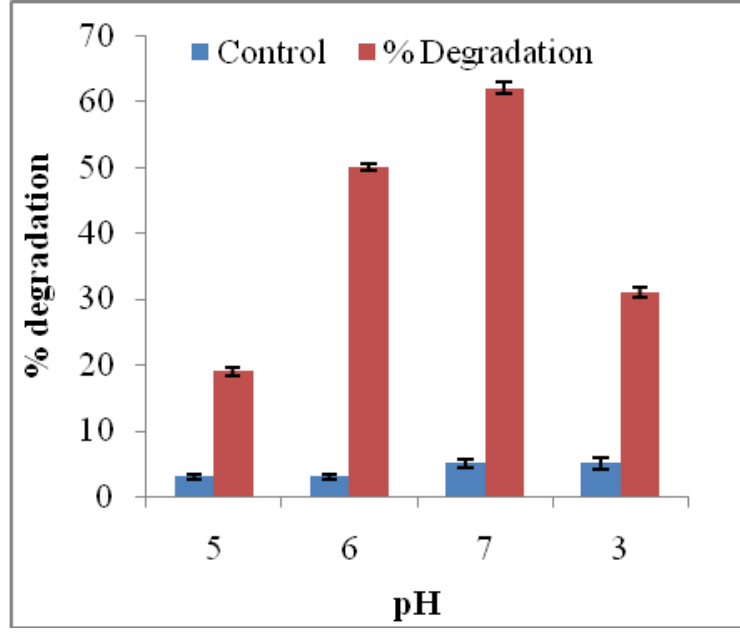

(c)

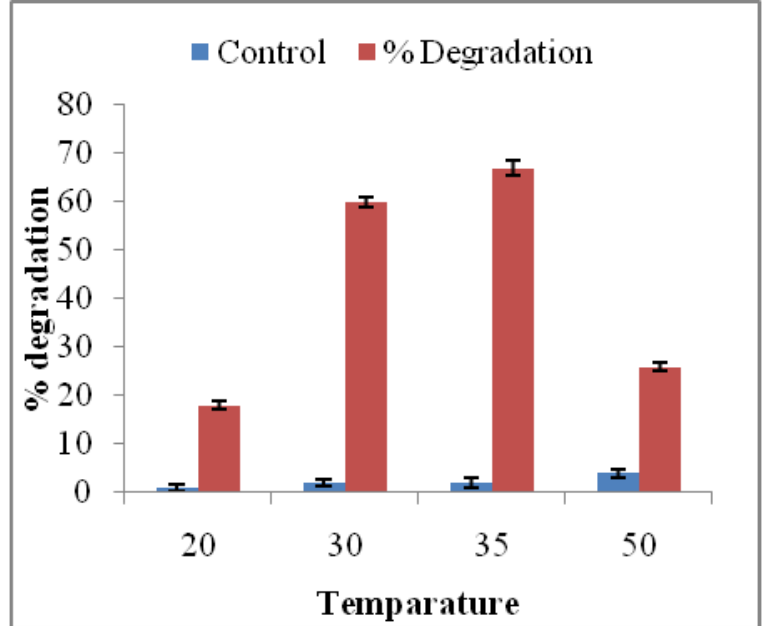

(b)

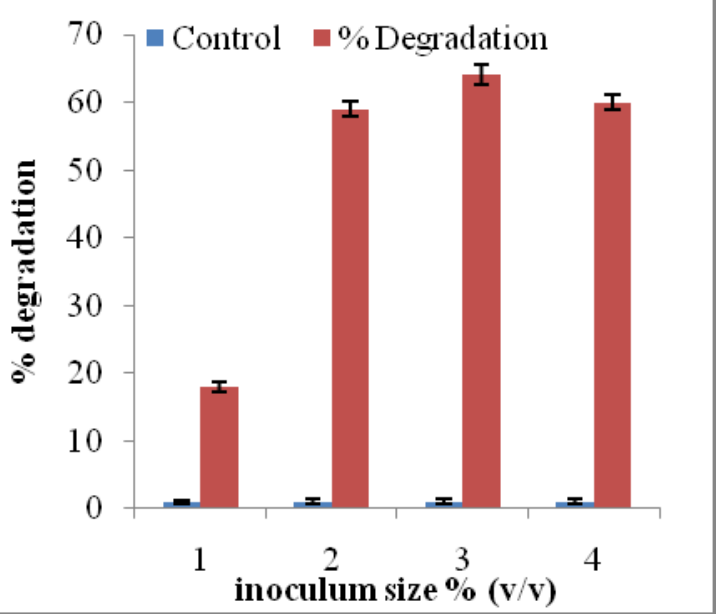

(d)

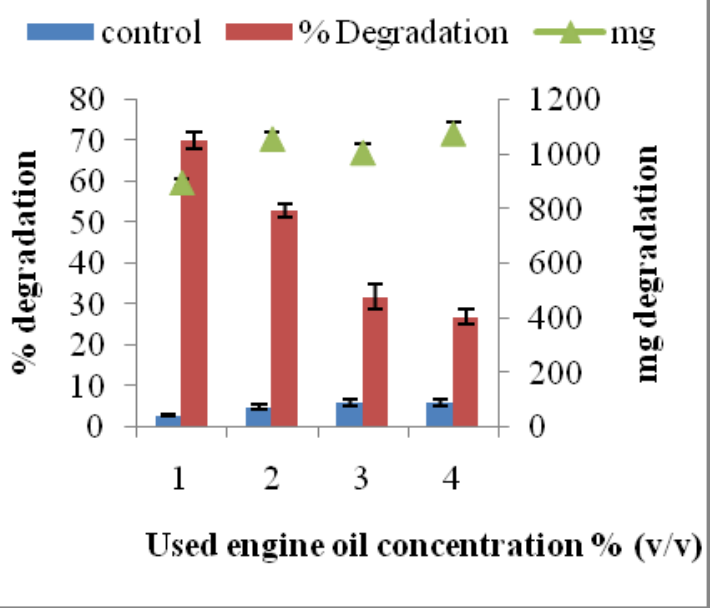

Influence of incubation temperature is shown in figure 3 (c), the optimum temperature was found to be $35 \pm 2{ }^{\circ} \mathrm{C}$ temperature and the degradation was 2.5 to 3.7 fold lower on either side of the optimum temperature compare to the highest degradation. This could be due to the mesophilic nature of the organism and the place of sampling, which had temperature around $35 \pm 2{ }^{\circ} \mathrm{C}$.

Influence of used engine oil concentration is shown in figure 3 (d), as the concentration of used engine oil increased percentage of used engine oil degradation was found to decrease. The $\%$ degradation was decreases in the range of 67 to $27 \%$ for 1,23 and $4 \%$ of used engine oil added. However as the amount of the added used engine oil was different, if the degradation was considered in terms of milligram of used engine oil degraded they were 900, 1060, 1010 and $1080 \pm 50 \mathrm{mg}$.

Screening test showed degradation of used engine oil by as many as 15 isolates. Out of these 15 isolates DP-1 showed the highest activity. It was identified as strain Pseudomonas aeruginosa DP-1. It showed oxidation 2, 6-DCPIP test. Optimization of oil degradation procedure resulted in as high as $69 \%$ used engine oil degradation. 
Developed culture can be used for the degradation of discarded used engine oil as well as for the cleaning of used engine oil contaminated soil.

\section{Acknowledgement}

We acknowledge UGC for providing research funding under RGNF scheme [F117.1/201617/RGNF201517SCGUJ1062/(S AIII)]. UGC emeritus fellowship is extended to senior author [F.6-6/2015-17/EMERITUS2015-17-GEN-7433/(SA-II)]

\section{References}

Adelowo, O. O., Alagbe S. O., and Ayandele, A. A. 2006. Time-dependent stability of used engine oil degradation by cultures of Pseudomonas fragi and Achromobacter aerogenes. Afr. J. Biotechnol. 5: 24762479.

Akio, U., Mohammad. H., Isao.Y. and Hidetoshi, O. 2006. Verification of Degradation of nalkane in Diesel Oil by Pseudomonas aeruginosa Strain WatG in Soil Microcosms, Curr. Microbiol., 52: 82-185.

Black, C.A., 1965. "Methods of Soil Analysis: Part I Physical and mineralogical properties". American Society of Agronomy, Madison, Wisconsin, USA.

Dominguez-Rusado, E., and Pitchel J., 2003. Chemical characterization of fresh and weathered motor oil via GC/MS, NMR and FITR Techniques. Proceedings of the Indiana Academy of Science 112: 109-116.

Hanson KG., Desai J.D., and Desai AJ., 1993. A rapid and simple screening technique for potential crude oil degrading microorganisms. Biotechnol Tech.; 7: 745_748.

Koma, D., Sakashita, Y., Kubota, K., Fujii, Y., Hasumi, F., Chung, S. Y. and Kubo, M., 2003.Degradation of car engine base oil by Rhodococcus sp. NDKK48 and Gordonia sp. NDKY76A.Biosci.Biotech.Biochem., 67:1590-1593.

Lal S, Khanna S., 1996. Degradation of crude oil by Acinetobacter calcoaceticus and Alcaligenes odorans. J. Appl. Bacteriol., 81: 355-362.

Lu S-T., and Isaac K., 2008.Characterisation of motor lubricating oils and their oil water partition. Environ Forens. 9: 295-309.

Qin, X. S., and Huang, G. H., 2009.Simulation and optimization technologies for petroleum waste management and remediation process control. Journal of Environmental Management, 90, 54-76.

Su WT., Wu B.S., and Chen W.J., 2011. Characterization and biodegradation of motor oil by indigenous Pseudomonas aeruginosa and optimizing medium constituents. J Taiwan InstChemEng 42: 689-695.

Udeani, T. K. C., Obroh, A. A., Okwuosa, C. N., Achukwu, P. U., and Azubike, N., 2009. Isolation of bacteria from mechanic workshops' soil environment contaminated with used engine oil. Afr $\mathrm{J}$ Microbiol. 8(22): 6301-6303.

Wang L., Wang L F-T., and Liu H., 2007. Treatment of engine oil polluted waste water with mixed bacterial floral and kinetics of biodegradation. J Chongqing Uni 6: 238-241.

\section{How to cite this article:}

Dipti R. Parikh, Devayani R. Tipre, Nisha S. Nayak and Shailesh R. Dave. 2018. Degradation of Discarded used Engine Oil by Pseudomonas aeruginosa DP-1 and Its Optimization. Int.J.Curr.Microbiol.App.Sci. 7(04): 2224-2229. doi: https://doi.org/10.20546/ijcmas.2018.704.253 